ISSN: 2162-3104 Print/ ISSN: 2166-3750 Online

Volume 8, Issue 4 (2018), pp. 1569-1590

(C) Journal of International Students

http://jistudents.org/

doi: $10.5281 /$ zenodo. 1467811

\title{
Motehen: A Case Study of Shifting Perceptions of Japanese Masculinity and Desirability Through Study Abroad
}

\author{
Elisabeth (Libby) Morinaga-Williams \\ Osaka University, Japan
}

\begin{abstract}
Topics of gender, sexuality and desirability have become prominent themes in study abroad research, particularly when exploring the experiences of Japanese women overseas. However, little research has explored the gendered experiences of Japanese male international students. This paper presents the case study of Ki, a young Japanese man who studied abroad in the United States. During his sojourn, Ki experienced a significant shift in his perceptions of masculinity and desirability through clashes with essentialized Western romantic practices and gender norms. This article critically examines discriminatory discourses of Japanese heterosexual masculinity and argues that colliding with these discourses negatively altered Ki's view of himself as a desirable romantic partner both during his sojourn and upon his return to Japan.
\end{abstract}

Keywords: desirability, identity, Japanese international students, masculinity, study abroad

Study abroad is often perceived by students and promoted by institutions as a once-in-a-lifetime opportunity, with chances for multicultural relationships, foreign language acquisition and lasting personal growth. As the globalization of higher education rises and international experience is seen as increasingly valuable for the neoliberal job market, short-term sojourns overseas are being promoted progressively on university campuses. Research on international student experience and study abroad has also grown in recent years in the social sciences, with many researchers moving 
away from traditional static concepts such as quantifiable measurements of language acquisition and cultural competence, to more critical perspectives on sojourner identity and marginalization. Such studies (e.g., Ellwood, 2011; Goldoni, 2017; Kinginger, 2013) have shed light on the complex and varied ways in which aspects of a student's identity such as race, linguistic background, socioeconomic status, sexuality and/or gender are challenged or take on new meanings by moving to a host country, resulting in shifts or conflicts in a sojourner's understanding of herself/himself and the surrounding communities. In the context of Japan, the gendered experience of Japanese female sojourners has become a major theme in study abroad research, particularly in predominantly English-speaking countries (e.g., Kelsky, 1996; 2001b; Kobayashi, 2007; Takahashi, 2013). Study abroad is chiefly a female phenomenon around the world and Japan is no exception (Kinginger, 2009; Ono, 2015), which may be one reason for the focus on the Japanese female experience. Particular interest has developed around what many researchers observe as a strong sense of longing for membership in Western communities, a desire for fluency in English, and romantic relationships with English-speaking "Western" partners among many Japanese female sojourners (e.g., Kelsky, 1996; 2001a; 2001b; Takahashi, 2013). This has resulted in a significant number of studies that focus on the gendered experiences and sexual relationships of Japanese women overseas and what their Western romantic partners can represent to these women. The experiences of Japanese men who study abroad, however, is an area that has received little attention and remains largely under researched, especially through the perspective of gender (Kato, 2015; Ono, 2015). Studies involving Japanese men abroad that have examined gendered experiences present in-depth research on masculinity in connection to work, family and the quest to know oneself (e.g., Kato 2013; Kato; 2015; Ono, 2015; Takayama, 2000). This limited research has suggested that study and shortterm work abroad for Japanese men is a gendered experience that takes on a very different form than that of their female counterparts, particularly concerning one's perceptions of masculinity and desirability as a Japanese man. In other words, while Japanese women in predominantly Englishspeaking countries are perceived as desirable romantic partners by men in their host communities, Japanese male sojourners exist among very different and even discriminatory discourses regarding their masculinity and desirability.

Inspired by this lack of previous research about the Japanese male experience reflected through masculinity and desirability, one of the main goals of this study was to investigate the gendered experiences of Japanese 
men who took part in study abroad programs during their time in university. Two general questions guiding this study were: (1) Do Japanese male university students see their study abroad experience as different than that of their female counterparts? (2) If so, how? This study uses Kinginger's (2009) definition of study abroad as "a temporary sojourn of predefined duration, undertaken for educational purposes" (p.11), and views a "sojourner" as a non-degree-seeking international student. This paper, which presents an expanded case study taken from master's thesis research, focuses on the accounts of $\mathrm{Ki}$, an education graduate student from Western Japan. Ki's accounts illustrate the ways in which his identity as an attractive heterosexual man was challenged through his undergraduate short-term study abroad in the United States.

\section{LITERATURE REVIEW}

The gendered study abroad experience of Japanese women has been investigated by several researchers over the last twenty years. Kelsky (1996) suggests that Japanese women in Western countries have been sexualized and exoticized under the gaze of Orientalism. Yet some studies have also explored the phenomenon of akogare, a widespread "longing, desire, or idealization" (Kelsky, 2001b, p. 26) of Western culture among Japanese women. Kelsky (1996; 2001b) and Takahashi (2013), who have extensively investigated akogare in Japanese women in Japan and overseas, claim that a love for essentialized Western pop culture such as films, music, and fashion were a powerful motivator in their participants' decisions to go abroad to study English, work temporarily, or simply to travel. These researchers argue participants' akogare was propelled by a lingering desire for idealized romantic relationships with Western, English-speaking (generally White) men. Thus, akogare has become a key component in the analysis of Japanese women and international experiences, particularly regarding study abroad in predominantly English-speaking countries. It has been further suggested that Japanese women may perceive marriage to White men as not only a form of self-internationalization but also a path to upward social mobility (Kelsky, 1999; Ono, 2015). Appleby (2013), who explored concepts of masculinity and desire through interviews with White male English teachers in Japan, asserts, "Japanese women's agentive desire, underpinned by a newly found economic independence and propelled by glamorous media images of Western romance, has accorded Western masculinity a privileged place in the Japanese imaginary" (p. 2). Much research views the gendered experience of sojourning Japanese women in 
connection with Western heteronormative masculinity and Japanese women's embrace of essentialized Western culture. This suggests that while these women may be sexualized within their Western host communities, their desirability among Western men also gives them the power choose which romantic relationships they would like to pursue (Takahashi, 2013).

Takahashi (2013), whose initial research included exploring the motivations to study English in Sydney of both young Japanese men and women, states that the men presented their motivations for studying abroad as "more or less straightforward and practical: English was necessary to get into an Australian university and an overseas qualification would be useful upon their return to Japan" (p. 1). Despite this observation, other research concerning Japanese male sojourners suggests complex and varied motivations and experiences. Kato's $(2013 ; 2015)$ interviews with young Japanese men studying English or participating in Working Holiday Visa programs in Canada and Australia illustrated engagements with jibunsagashi, or "self-searching", full of deep-rooted reflection on careers, relationships and self. Moreover, akogare is not an exclusively female phenomenon, as illustrated by Ellwood (2011) and Takayama's (2000) interviews with Japanese males studying abroad who also articulated akogare for essentialized Western pop culture. The young Japanese men in Takayama's (2000) study moreover expressed a strong desire to have "Canadian" friends, which the author points out frequently denoted White native English speakers. His participants spoke at length about a romantic attraction to, and admiration of, the White Canadian women they encountered during their sojourn. Takayama concluded that his participants otherized White Canadian women through idolizing them, resulting in such a strong sense of difference that made "it unthinkable for them to be in an intimate relationship with [White women]" (p. 106). This sense of difference is also embodied, since several of participants developed a strong awareness of their physical appearance after coming to Vancouver and believed that they were unattractive by idealized Western standards of hegemonic masculinity, citing reasons such as being too short or too skinny and weak. In this way, some participants felt emasculated or marginalized by White women, despite their limited interactions. Both Appleby's (2013) and Kelsky's (2001a) interviews with White foreign men in Japan validate these concerns, given that Japanese men were generally portrayed as both romantically and physically inferior to White (particularly Englishspeaking) men.

In recent years, the popular Japanese media has drawn new images of the current generation of young Japanese men, all of which present 
challenges to the hegemonic discourse of traditional masculinity in Japan. Aoyama (2015) and Ono (2015) introduce three prominent examples of opposition to hegemonic Japanese masculinity, which include otaku ("comic book geeks"), hikikomori ("shut-ins") and soshokudanshi ("herbivore boys"). While the discourses of otaku and hikikomori are largely applied to men, they can technically refer to women as well. However, soshokudanshi refers exclusively to Japanese men and has become a familiar term in everyday discourses. This term sharply contrasts young Japanese men with their sarariiman (salaryman) fathers and grandfathers, who became a prominent symbol of hegemonic masculinity in postwar Japan until the bubble burst at the end of 1990. Unlike the sarariiman, who were "expected to display loyalty, diligence, dedication and self-sacrifice" (Dasgupta, 2003, p. 123) to their company, soshokudanshi have a lack of interest in the conventional career path of older generations and shy away from the traditional full-time, permanent employment path with long and inflexible working hours. Soshokudanshi are painted as passive and weak, and believed to spend much more time on their appearance than older generations, even utilizing male beautification products (Koike, 2013). The most notable belief about herbivore boys is that although heterosexual, these men have a striking lack of interest in sex and marriage. Consequently, they do not actively pursue women for courtship or sex. Koike's (2013) detailed account of the discursive construction of soshokudanshi in the Japanese media argues that the idea of herbivore boys, who "combine femininity with masculinity" (p. 37), present a challenge to the heteronormative discourse of Japanese masculinity. He also comments that both older men and young women invoke negative discourses of soshokudanshi to express their disappointment with the current generation of young Japanese men. Hence, existing literature suggests that both Japanese women and Japanese men may hold akogare towards essentialized ideals of Western culture and romantic partners, and yet the two groups occupy very different spaces within the realm of study abroad. While Japanese women are often perceived as appealing romantic partners, Japanese men must grapple with negative discourses of "herbivorism" and challenges to their own perceptions of acceptable cultural and embodied masculinity, implying that the experience of study abroad takes a very different form for Japanese men and warrants further research. 


\section{RESEARCH METHOD}

\section{Theoretical Framework}

This research uses a critical approach to data collection and analysis. In the field of study abroad research, a critical approach notes that discourses surrounding sojourners and their communities abroad and at home are value-laden and consequently connected to relations of power. A critical approach has the potential to challenge taken for granted assumptions through investigating how discourses are created, reproduced or resisted (Taniguchi \& McMahill, 2015). Exploring the lived experiences of individuals is of importance given that it is through these lived experiences that insight can be gained into how discourses manifest and affect individuals, and how individuals uphold or challenge these discourses in their everyday lives. Ultimately, by exposing and problematizing assumptions that are essentialist and marginalizing, a critical approach seeks to create counter-discourses to deconstruct harmful power hierarchies.

Identity has become a recurring theme within applied linguistics research in recent years, with many social scientists moving away from modernist approaches that view identity as static and inherently connected to biological traits such as sex or race (Block, 2007). This study employs Norton's (2000) definition of identity as "how a person understands his or her relationship to the world, how the relationship is constructed across time and space, and how the person understands the possibilities for the future" (p. 5). Encounters with the social world construct, reproduce and challenge relations of power, which contribute to shaping an individual's diverse and complex identity. However, individuals may also claim agency to create counter-discourses that allow them to enact desired identities even when they are in positions of marginalization. Identities are multiple, dynamic and contradictory in connection to the social world, and are not only fluid but also "a site of struggle" (Norton, 2000, p. 127) when the social world and human agency collide. Norton points out that an individual may connect with, utilize, feel empowered by or even oppressed by an aspect of their identity at a given time-for example, caretaker, immigrant, female, language learner, and so on. This dynamic approach to identity is utilized when exploring Ki's gendered and national identity as a Japanese man overseas.

\section{Methodology}

Although the case study presented focuses solely on Ki's accounts, this article uses data originally collected from 2013 to 2014 for a master's thesis. The goal of this graduate research was to gather in-depth accounts from 
returned Japanese university student sojourners to learn about their perceptions of the affects of study abroad and returning home on their identities. Their personal accounts were then analysed in connection to wider social discourses regarding nationality, gender, and language. Because of the desire to elicit extensive data containing personal opinions and stories, multiple qualitative semi-structured individual interviews were chosen as the method of data collection. Data was collected over approximately five months from interviews with six Japanese students at a private university in Western Japan (given the pseudonym "K University"). Participants were recruited by snowball sampling through the researcher's personal networks at K University. Interviews were conducted in a mixture of Japanese and English, given that all participants and the researcher are bilingual in English and Japanese.

Each participant was interviewed three times. The first interviews focused on participants' experiences abroad, while the second interviews inquired about participant experiences since returning to Japan. The final interviews held the main goal of member checking, where participants were shown the researcher's initial impressions and interview transcripts and then asked to provide feedback and reflect on the interview experience. Ki's accounts were re-analysed for this article with a focus on discourses surrounding masculinity, desirability and gender.

Interviews were recorded on a personal recording device and first transcribed exactly as they were spoken shortly after the interviews took place. To convey the environments in which utterances were created, word stress, laughs, pauses, and notable gestures were included in transcription to the best of the researcher's ability using Roulston's (2010) transcription guidelines. Inductive thematic analysis was used to create codes and themes to explore commonalities and differences in participant accounts. Analysis followed Braun and Clark's (2006) outline of transcribing oral interviews, creating codes, grouping codes into themes, reviewing themes, analyzing themes and synthesizing themes before creating the final report. The researcher viewed transcripts several times and manually took notes of codes before grouping them into themes. Interview transcripts used in the final report were also translated into English for the ease of predominantly English- speaking readership. Utterances that were originally stated in Japanese are italicized in the transcript excerpts in the Findings section of this paper. A transcription key is also provided at the beginning of the Findings section. 


\section{Participant}

At the time of the interviews, Ki was a second-year English language education master's student at K University. Ki's goal was to be a junior high school English teacher in Japan after graduation. He had gone to North America as an international student three times since entering university. His first sojourn, which was the focus of our interviews, was a six-month stint in the state of Washington during the second year of his undergraduate degree. He took sheltered classes for K University students at a partner university for approximately four months but later moved to English as an additional language (EAL) classes for the remainder of his stay to specifically focus on improving his English language proficiency. Next $\mathrm{Ki}$ went to California for a month-long internship with a Japanese trade company and then to British Columbia for a summer program as a graduate student. At the time of data collection, $\mathrm{Ki}$ was preparing to leave for a tenmonth-long study abroad program in Australia with the hope of further improving his English, despite this adding extra time to his master's degree. $\mathrm{Ki}$ was introduced to me by a professor at K University who worked closely with him during his graduate studies. When speaking with Ki's classmates and his research supervisor, it appeared to be common knowledge that $\mathrm{Ki}$ was a charismatic and well-liked man who was popular with women. While all male participants in the original study spoke of challenges to their previously established ideas of male desirability through study abroad, Ki's accounts were selected and further investigated for this article because his perceptions of masculinity and romantic relationships became the prime focus of our interviews. Ultimately, the challenges to his identity as a desirable romantic partner triggered during his time abroad lingered with him after his return to Japan the most in comparison to other participants.

\section{Limitations}

This study's first limitation is that data was largely collected in the researcher's second language (Japanese). Despite interview transcripts being checked by native Japanese speakers, there is a possibility that misunderstandings occurred between $\mathrm{Ki}$ and the researcher during the interviews. Choosing to present Ki's experience as a case study also restricts research generalizability, although it does provide an in-depth and worthwhile look into one participant's experience (Duff \& Anderson, 2016). While Ki's accounts reflect and problematize wider discourses and essentialized assumptions regarding masculinity and heterosexual romantic expectations in society, his experiences should not be seen as representative of all Japanese males who study abroad in English majority countries. It is 
further important to note that Ki's accounts refer exclusively to men in heterosexual romantic relationships and this should be kept in mind when viewing the excerpts and the discussion that follows this section.

There is always the probability of essentialism when Western researchers investigate other countries and cultures, and therefore the researcher's identity as a White female North American English speaker prompts the need for the critical analysis of researcher subjectivity. Lee and Simon-Maeda (2006) highlight this problem by asserting that despite the White feminist researcher's "best intentions", she "may in fact reproduce the same oppressive conditions she claims to be concerned about" (p. 575). Moreover, in this study, the researcher was not only aware that she is an "outsider" creating an analysis of the experiences of Japanese heterosexual male sojourners, but also that "White, North American women" is a group to which $\mathrm{Ki}$ frequently referred in his accounts. It is possible that $\mathrm{Ki}$ restrained himself when speaking about these women in an attempt not to offend the researcher. This significant issue will be further explored in the Discussion section of this paper. Finally, although data was collected largely in Japanese and explore discourses of heterosexual Japanese males, the relevant literature referenced draws exclusively from previous studies conducted in English. Including Japanese language sources in the future would create a more comprehensive analysis.

\section{FINDINGS}

The topic of being motehen was one that $\mathrm{Ki}$ and the researcher discussed at length. In standard Japanese, moteru or motenai are common terms that respectively describe someone's popularity or lack of popularity, especially with the opposite sex. Ki uses his regional dialect to state that Japanese men are not desirable romantic partners to Western women; in other words, that they are motehen. The following two interview excerpts were chosen for this paper because they are representative of $\mathrm{Ki}$ and the interviewer's lengthy discussions of being moteru or motehen. Within these accounts, Ki presents two main reasons for Japanese men being motehen: (1) Being physically unattractive to non-Japanese women and (2) not participating in expected romantic customs. The first interview excerpt focuses on the former issue. This interview took place in a local café nearby Ki's university on a weekday evening after dinner. Previously, $\mathrm{Ki}$ and the researcher had been discussing his experience of being painted as a "shy" Japanese student in his university classes in Washington, when the researcher changed the topic to directly inquire about his experience as a Japanese man overseas. 
Table 1. Conventions used in interview transcriptions.

\begin{tabular}{ll} 
Symbol & Meaning \\
\hline$@($ Brief laugh \\
@@ & Long laugh \\
$()$. & Short pause \\
$::$ & Elongated sound \\
$\underline{\text { friends }}$ & Emphasis \\
${ }^{\circ}$ friends ${ }^{\circ}$ & Words spoken in a whisper \\
[taps table] & Description of action \\
\hline
\end{tabular}

Interview 1, October 2013: Zenzen motehen de! (We aren't popular at all!)

I (Interviewer/researcher): Okay, so one thing that I'm really curious about is, in research, there's almost no information about Japanese men's experience

$\mathrm{K}(\mathrm{Ki}): \mathrm{Oh}$ !

I: So, what about [breathes out] did you ever feel like, or how did you feel as a Japanese man.

K: Man.

I: It's a bit strange

$\mathrm{K}:$ Ah, I see!

I: of a question.

K: Well okay well okay. Ah:: My experience. Not only my experience. But there's an image of Japanese women as popular with men

I: M::hm

K: With foreigners. And they easy to get, like Japanese girl easy to get (.) American or Canadian boyfriend. But Japanese man is face difficulties@@

I:Poor them@@

K:Yeahyeahyeah@@

I:@Isee. 
$\mathrm{K}$ : Yeah yeah yeah probably it's because people say that Japanese men are short, or let me see. We aren't popular at all! (zenzen motehen de!)

I: No::

K: Probably. Yeah.

I: Really, you felt that?

K: Yeah yeah yeah. When I spoke with those people I felt that.

I: $\mathrm{Hm} \mathrm{hm.}$

K: They never care about Japanese men I think.

I: Yeah.

$\mathrm{K}: \mathrm{Mmhm}$.

I: You're talking about White women?

$\mathrm{K}$ : Yeah yeah yeah.

I: Ah::

$\mathrm{K}$ : I think they have no interest

I: ${ }^{\circ} \mathrm{Oh}^{\circ}$

K:@@It's a stereotype but

I: Hmhmhm.

Ki's accounts focused mostly on his longest sojourn, which was his stay in Washington. When asked about if he felt there was anything unique to study abroad specifically as a Japanese man, $\mathrm{Ki}$ immediately connects being a Japanese man abroad and romance with "foreign" women, specifically focusing on the challenges he and other Japanese men had in dating North American women ("American or Canadian") overseas. This struggle is compared to the success of Japanese women who Ki believes are generally popular with non-Japanese men. Ki provides two main reasons for Japanese men being motehen in North America, with these reasons being both physical and relational. Specifically, Japanese men are "short" and North American women "never care about Japanese men." Through comparing moteru Japanese women overseas to Japanese men who "face difficulties" in romance, Ki's accounts present perceived shortcomings of Japanese men and illustrate $\mathrm{Ki}$ colliding with new and destabilizing discourses during his sojourn that challenged his perceptions of his own desirability and 
masculinity. Considering that he had an active dating life in Japan, it is no surprise that Ki assumed he would date during his sojourn. Later in the same interview, the researcher asked, "And were you searching for a girlfriend as this time?" and $\mathrm{Ki}$ states that although he was at first looking for an American girlfriend, he eventually concluded that "zettaini muri da to omoimashita ne" (I thought that it was absolutely impossible).

Ki's accounts also contain essentialized images of all key players in this narrative: Japanese and North American men and women. Firstly, the women who are not interested in Japanese men are White women, which may also be attributed to the researcher directly asking $\mathrm{Ki}$ who he was referring to by "they" in "They never care about Japanese men I think." Although Ki states that White women having no interest in Japanese men is just a "stereotype," he emphasizes a significant imbalance between Japanese men and women's dating successes overseas. This is also connected to the discourse of the widespread popularity of Japanese women as romantic partners for North American men.

Ki's second interview took place in a vacant university classroom at Ki's university on a weekday afternoon. The researcher and $\mathrm{Ki}$ first reflected on his prior interview and the idea of Japanese men being motehen continued to be a main topic of discussion. The next excerpt highlights how, in Ki's perspective, Japanese men are unable or unwilling to take part in expected Western romantic practices, specifically those that surround outward displays of affection. This conversation was proceeded by the researcher and $\mathrm{Ki}$ discussing why international marriage rates between White women marrying Japanese men versus White men marrying Japanese women were significantly different.

\section{Interview 2, December 2013: Japanese men don't say I love you at all}

$\mathrm{K}$ : And white, not only White guys but many, how can I say this? Foreign men, White men, Black men, people who

I: not Japanese

K: not Japanese

I: just besides Japanese?

$\mathrm{K}$ : Yeah yeah yeah. Treat treat their women very carefully and goodly

I: Ah@ Japanese men don't?

$\mathrm{K}$ : No no no no no 
I: What? Really? What about your, your situation with your girlfriend?

K: No.

I: What? Why?

$\mathrm{K}$ : How can I say this? What should I say? I don't do this [punching action]@

I: @

K: @ Of course. But I don't punch or kick. I don't. At all. But, how can I say this? Like, with Americans I have that image, it's my own personal image of like, Canadians, maybe. Like they always say I love you and give the flowers.

I: Yeah::

K: Such as for anniversary (.) Don't they do that?

I: Yeah. They have to a

$\mathrm{K}:$ They have to, right?

I: @

$\mathrm{K}:$ But Japanese men

I: $\mathrm{Mmhm}$

$\mathrm{K}$ : don't say I love you at all.

I: Hm.

K: Maybe once a year. Or (.) Not even once. How do you say not even once a year in English?

I: Sorry? Once

$\mathrm{K}$ : Once a year

I: Just once a year or not even once a year?

$\mathrm{K}$ : Not even once a year. Yeah, not even once a year. Yeah.

In this excerpt, the discussion moves past the physical appearance of Japanese men to their participation in idealized Western dating practices. Japanese men are again presented as the losing group, this time falling short of foreign men who are more appealing partners because of how well they "treat their women," such as regularly saying "I love you" or giving flowers. 
While this is justified as cultural, illustrated by both $\mathrm{Ki}$ and the researcher constructing essentialized expectations of Western heterosexual men, Ki believes it is something that women, regardless of cultural background, desire. He is adamant that Japanese men don't say "I love you" but stated "women need it," meaning women need to be told they are loved. This inability, or refusal to outwardly express affection accounts for another reason why Japanese men are supposed undesirable romantic partners. Hence, in addition to North American women avoiding dating Japanese men, Ki claims Japanese women also prefer non-Japanese partners given the latter's willingness to openly express affection.

This excerpt further exemplifies discourses concerning the essentialized groups described in Ki's accounts. Heterosexual Japanese men are seen as unromantic, or at least unwilling to display affection, while women are portrayed as requiring this open affection from their partners in order to be satisfied. Finally, all men "besides Japanese" are naturally inclined to display such love. Through creating these static images, Ki not only justifies the perceived shortcomings of Japanese men as something intrinsically linked to identities as "Japanese" and "male," but also justifies the supposed success of non-Japanese men in romance. As international student identities may be destabilized when coming into contact with new discourses abroad (Ellwood, 2011), Ki's use of essentialism of Japanese men (himself included) and the remaining groups both rationalizes successes and shortcomings in romance and returns stability to his perceptions of who he is as a heterosexual Japanese male. In other words, it helps account for why he was no longer moteru abroad.

\section{DISCUSSION}

\section{Ki's Conflicts of Identity and Use of Essentialism}

While $\mathrm{Ki}$ and the researcher often spoke in a light-hearted fashion during the interviews, the prejudice Ki experienced abroad is salient in his accounts and should be critically examined. Each student that goes abroad brings with them perceptions of herself or himself and how she or he expects, or at least hopes, to be viewed by others. Blommaert (2006) categorizes these "expectations" as two dimensions of identity: "ascribed" identities, which are identities placed onto us by others; and "inhabited" identities, or identities that we attempt to claim and enact (p.174). Using this framework is helpful when considering the conflict surrounding Ki's identity as a single Japanese man given the identity he wished to embody (moteru) and how he felt he was received (motehen) abroad by North 
American women. Norton (2000) illustrates the distress that such conflicts can cause within a person, especially when that person holds a potentially marginalizing status, such as an international student. While Ki experienced being moteru in Japan, he was not able to transport this identity with him during his studies in Washington, thus destabilizing his view of himself and perceptions of what constitutes desirable masculinity in a heterosexual man. This further led him to question his overall potential as a romantic partner-doubt that seemed to linger with him even after returning to Japan and beginning to date again.

Ki's accounts mirror that of Takayama's (2000) interviews with young Japanese men sojourning in Vancouver in several ways. Namely, both Ki and Takayama's participants' accounts contain gendered and racialized discourses that intersect to paint relationships with Western (predominantly White) women in a complex light of akogare, essentialism and uneven relations of power. Western women may have been desirable, but participants viewed them as unattainable due to their supposed disinterest in Japanese men. This disinterest was thought to be based on physical and relational shortcomings of Japanese males, just as Ki states. While he felt inferior to these women due to both his race and gender, the juxtaposition of the moteru image of Japanese women and Western men (which he described mainly as White and Black) illustrates how it was not merely his gender or nationality that marginalized $\mathrm{Ki}$, but a combination of the two.

Yet Ki's struggles with his identity and being moteru or motehen are not limited to the self, reflected in his essentializing remarks about the other groups described in his accounts. Kubota (2003) points out that essentialism not only proposes negative fixed traits about a group but potentially positive or complimentary ideas as well, as exemplified in Ki's portrayal of Japanese women as moteru overseas or Western men as romantic gentlemen. Even though these are not necessarily negative traits, they are nonetheless problematic, given that such comments neglect the vast individual differences among a group in addition to disregarding how context and interlocutors give rise to different courses of actions. Hence these complimentary essentialist ideas still limit and categorize. Simply put, it is not the case that all Japanese men refuse to say, "I love you," that all women need open affection from their partners, or that all Western men give their partners flowers. Through essentializing these groups, similar to Takayama's (2000) participants, Ki creates a sense of otherness among the agents in his narrative, leading to categories of "us" (Japanese men) and "them" (others). Given his previous moteru status in Japan, Ki's essentialism of Japanese men may have been employed to create a stable 
gendered identity for himself and other heterosexual Japanese men facing similar turmoil of marginalizing discourses that threatened their perceptions of masculinity and desirability. By framing himself and other Japanese men in this way, the struggles $\mathrm{Ki}$ experienced in dating are not due to fluctuating socially and historically constructed images of Japanese men, but instead simplified as the result of intrinsic traits that all Japanese men possess. It is also worth noting that despite the popularity at the time of interviews of the word soshokudanshi, Ki did not describe himself or Japanese men with this term and rather illustrated a keen interest in dating both during his study abroad and after his return to Japan. This supports Koike's (2013) conclusion that many young Japanese men, despite often being described as "herbivores," do not identify with or fit the passive label that the media and older generations have created for them.

\section{Pervasive Marginalizing Discourses About Japanese Men}

Overall, Ki's accounts emphasized his ideas of both physical and cultural inadequacies of young heterosexual Japanese men. Japanese men are portrayed as small, uncharismatic, poor communicators and unromantic; as men who are unable to reach the essentialized and idealized standard of Western romance. Ki's statements are reflective of not only his defence to his feelings of marginalization, but are also illustrative of pervasive, problematic societal discourses of heterosexual Japanese men. Ki may have been aware of these discourses before going to Washington but had yet to personally encounter them. Through his study abroad, Ki collided with the discriminatory images of Japanese men and essentialized Western masculinity that raised within him a lasting awareness of the prejudicial images of heterosexual Japanese men. A comment from a Japanese female participant in Kesky's (1999) study represents this sentiment well:

Japanese guys feel more inferiority than girls do that they are racially despised by the world. With Japanese girls, you are popular just for being a Japanese girl. For us, it's almost an advantage. But Japanese men have no standing (tachiba ga nai). Race becomes a problem for Japanese men, but for Japanese women, race is excused (yuruseru). (p. 101)

Images of Japanese men as inferior romantic partners for women can be found in both academic literature and popular culture. For example, through interviews and personal anecdotes, Appleby (2013), Kelsky (1996; 2001a, 2001b) and Simon-Maeda (2011) observed similar ideas both in Japan and the United States that positioned Japanese men as romantically and 
physically inferior to Western men (men who participants generally described as White or Black). Western men living in Japan who were interviewed regarding romantic relationships with Japanese women described themselves as more attentive, caring and communicative (Appleby, 2013), and even better lovers (Kelsky, 2001a). As White, English-Japanese bilingual women who lived in Japan with Japanese husbands, both Kelsky and Simon-Maeda collided with the "unspoken code" (Kelsky, 2001a, p. 432) that permitted White men to have Japanese girlfriends or wives while rejecting White women being involved with Japanese men. It seems the construction of the legitimacy of heterosexual Japanese masculinity is twofold: first, through positioning Western and Japanese men in competition with each other for women's affection, and next, women's acceptance or rejection of these perceived masculinities (Appleby, 2014; Kelsky, 2001a).

Such discriminatory double standards display marginalizing discourses that contribute to a hierarchy of power and desirability, with White males (especially English speakers) at the top, both in the West and in Japan. Ki's accounts reflect just this. Although Japanese women are attractive partners to "other countries' guys," Japanese heterosexual masculinity lacks both the physical and social attributes of a desirable romantic partner under the hegemonic discourses of Western romantic ideals. Ki clearly demonstrated frustration with this discriminatory system and yet he has internalized his so-called shortcomings. He even expresses a sense of powerlessness concerning creating counter discourses about the way he wished to be viewed as a single heterosexual Japanese man, as illustrated in his statement of "zettaini muri da to omoimashita ne" (I thought that it was absolutely impossible). Ki bringing this belief back with him to Japan after his sojourn exemplifies how identity can be a "site of struggle" (Norton, 2000, p. 127) for study abroad participants, even after they return from their sojourn. Ki's marginalization is further complicated by his observation that Japanese women, both abroad and in Japan, have much more ease in finding nonJapanese partners. Similar to the participants in Takayama's (2000) study, $\mathrm{Ki}$ felt that the combination of "Japanese" and "male" is a disadvantage in the context of romance and study abroad in Western countries, while "Japanese" and "female" is an advantage. Such observations again illustrate the hierarchy of desirability where Japanese men are placed at the bottom. Unequal distributions of power in the social world can restrict an individual's access to desired communities, resulting in fewer opportunities for interaction with and legitimacy within that community (Norton, 2000), which has the potential to significantly impact one's study abroad 
experience. It is not unreasonable to imagine that $\mathrm{Ki}$ had fewer opportunities to interact with his host community due to his feelings of marginalization and lack of confidence in his desirability abroad.

The construction of the essentialized Western standard of masculinity and heterosexual romance is widespread in Japan, often painting White men as sensitive, supportive, and kind lovers, not to mention handsome and charismatic. Such images have been found in eikaiwa (English conversation schools) advertisements (Bailey, 2006), English language learning apps (Kennett \& Jackson, 2014), comic books, like the famous My Darling is a Foreigner (Ogurai, 2002), and of course TV programs (Kelsky, 2001a). Essentializing and marginalizing portrayals of Asian males in the Western media are also easy to find. Some of most obvious instances are the tropes of the brainy, uncool and awkward Asian boy or the male Asian comic relief with exaggeratedly poor English. Long Duk Dong from Sixteen Candles (1986) and Mr. Yunioshi in Breakfast at Tiffany's (1961) are famous (and blatantly racist) examples from film. While these characters are now somewhat dated, a quick Internet search brings up blogs, videos, and online magazine articles with similar concerns and frustrations over essentialized notions of Asian males in the West. Another telling example of the marginalized position Asian men hold is The ABCs of Attraction, an American company that claims to be "The World's \#1 Asian Dating Coach," and states they are "known for our ability to turn even the most fobby Asian into a total player" (ABCs of Attraction, n.d.). Clearly, discriminatory discourses relating to Japanese men (and often Asian men in general) and Japanese heterosexual masculinity are pervasive in both Western and Japanese contexts. Ki's accounts illustrate some of the harmful consequences such discourses can have on Japanese men's sense of desirability and identity.

\section{Researcher Reflexivity and Co-construction of Gender Norms}

Kato (2007) argues that the topic of Japanese female sexuality has become an acceptable topic of research among female North American feminist academics, but a lack of critical reflexivity in many of these studies has had the unfortunate result of further essentializing and othering Japanese women. Although this differs in several ways from the present study, it raises the crucial point that critical feminists are not exempt from examining their positionality in research, and thus, there is substantial room to explore how the researcher participated in Ki's accounts. In continuing this section, I would like to use a more personal tone. After reanalyzing our interview transcripts, it is clear to me that I collaborated with $\mathrm{Ki}$ in creating images of 
Western men and gender roles during interview accounts. This is especially clear in the second interview transcript when I comment, "Yeah. They have to" in reference to American and Canadian men giving flowers for anniversaries. My comment may have been said in jest but nonetheless it contributes to the essentialized images of heterosexual Western men and the romantic roles they (and by proxy, their female companions) are expected to fulfill. Referring again to Lee and Simon-Maeda (2006), my interactions within the interview suggest constant and critical researcher reflexivity is crucial when White Western researchers interact with participants from nonWestern cultures, if our goals are to challenge, as opposed to uphold, already existing constructs of power.

\section{CONCLUSION}

Ki's accounts show an international student whose expectations for life abroad were not only unmet, but whose identity as an attractive heterosexual man was destabilized and ultimately altered even after his sojourn. Upon returning to Japan, he maintained the belief that Japanese men were the least appealing partners due to both their physical appearance and inadequate participation in dating practices. This idea eventually extended past interactions with non-Japanese women to those with Japanese women as well. Ki's accounts demonstrate how even short-term study abroad can have a lasting effect on a sojourner, prompting the need for a more critical approach to common discourses surrounding the Japanese male experience during study abroad, particularly the discrimination faced around gender, desirability and masculinity. Essentialist and marginalizing images of young Japanese men overseas and in Japan, such as the discourse of soshokudanshi and Japanese men as inadequate romantic partners in comparison to hegemonic Western standards, must continue to be challenged-not only through research but also through shifts in popular culture. The idealization of Western romance and heteronormative gender roles, which have long gripped individuals participating in akogare, require continued and significant attention. Similar to Kato (2007), who expressed deep concerns regarding North American feminist academics' approach to Japanese sexuality, Appleby (2013) notes that female researchers like this researcher are often the "voices" that speak about issues of male gender and sexuality, suggesting a pertinence to hear more about the Japanese male international student experience from the men themselves. Through continued qualitative research that examines the Japanese male experience both abroad and in Japan, research and its application may be able to alleviate marginalizing 
discourses by sharing not only about participants' shifting gendered identities, but also how they challenge, change or succumb to dominant discourses.

\section{REFERENCES}

ABCs of Attraction. (n.d.). About. Retrieved from http://abcsofattraction.com/ bootcamp/about-us/

Appleby, R. (2013). Desire in translation: White masculinity in TESOL. TESOL Quarterly, 47, 122 - 147. doi: 10.1002/tesq.51

Bailey, K. (2006). Marketing the eikaiwa wonderland: Ideology, akogare, and gender alterity in English conversation school in Japan. Environment and Planning, Society and Space, 24, 105 - 130. doi: 10.1068/d418

Block, D. (2007). Second language identities. London: Continuum.

Braun, V., \& Clarke, V. (2006). Using thematic analysis in psychology. Qualitative Research in Psychology, 3, 77-101. doi: 10.1191/1478088706qp063oa

Blommaert, J. (2006). How legitimate is my voice? A rejoinder. Target, 18, 163 176. doi: 101.1076/target.18.1.09blo

Dasgupta, R. (2003). Creating corporate warriors: The "salaryman" and masculinity in Japan. In K. Louie \& M. Low (Eds.), Asian Masculinities: The meaning and practice of manhood in China and Japan (pp.118 - 134). London: Routledge, Taylor Francis Group.

Duff, P. \& Anderson, T. (2016). Case study research. In J.D. Brown \& C. Coombs. (Eds.), Cambridge guide to language research. Cambridge: University Press.

Ellwood, C. (2011). Undoing the knots: Identity transformations in a study abroad programme. Educational Philosophy and Theory, 43, 960-978. doi:10.1111/j.1469-5812.2009.00559.x

Goldoni, F. (2017). Race, ethnicity, class and identity: Implications for study abroad. Journal of Language, Identity \& Education, 16, 328-341. doi: 10.1080/15348458.2017.1350922

Kato, E. (2013). Self-searching migrants: Youth and adulthood, work and holiday in the lives of Japanese temporary residents in Canada and Australia, Asian Anthropology, 12, 20-34. doi: 10.1080/1683478X.2013.774309

Kato, E. (2007). The sad marriage of anthropology, neo-colonialism and feminism: Or why Japanese sexual behavior is always intriguing. Asian Anthropology, 6, 81-103. doi: 10.1080/1683478X.2007.10552570

Kato, E. (2015). When a man flies overseas: Corporate nationalism, gendered happiness and young Japanese male migrants in Canada and Australia. Asian Anthropology, 14, 220-234. doi: 10.1080/1683478X.2015.1115580

Kelsky, K. (1996). The gender politics of women's internationalism in Japan. International Journal of Politics, Culture and Society, 10, 29 - 50. Stable URL: http://www.jstor.org/stable/20019872 
Kelsky, K. (1999). Gender, modernity and eroticized internationalism in Japan. Cultural Anthropology, 14, 229-255. Retrieved from http://www.jstor.org/ stable/656564

Kelsky, K. (2001a). Who sleeps with whom, or how (not) to want the West in Japan. Qualitative Inquiry, 7, 418-435. doi: 10.1177/ 107780040100700402

Kelsky, K. (2001b). Women on the verge: Japanese women, Western dreams. Durham, NC: Duke University Press.

Kennett, B. \& Jackson, L. R. (2014). 'What if your boyfriend was a foreigner?' Romance, gender, and second language learning in an edutainment context. Asian Englishes, 16, 152 - 172. doi: 10.1080/13488678.2014.916527

Kinginger, C. (2009). Language learning and study abroad: A critical reading of research. New York: Palgrave Macmillan Ltd. doi: 10.1057/9780230240766

Kinginger, C. (2013). Identity and language learning in study abroad. Foreign Language Annals, 46, 339 - 358. doi: 10.1111/flan.12037

Kobayashi, Y. (2007). Japanese working women and English study abroad. World Englishes, 26, 62.

Koike, E. (2013). Gendering knowledge in discourse on Japan's herbivore boys. Retrieved from ProQuest Digital Dissertations. 1544948.

Kubota, R. (2003). Critical teaching of Japanese culture. Japanese Language and Literature, 37, 67 - 68. doi: 10.2307/3594876

Lee, E. \& Simon-Maeda, A. (2006). Racialized research identities in ESL/EFL research. TESOL Quarterly, 40, 573 - 594. doi: 10.2307/40264544

Ogurai, S. (2002). Daarin wa gaikokujin [My darling is a foreigner]. Tokyo: Media Factory.

Ono, M. (2015). Descending from Japan: Lifestyle mobility of Japanese male youth to Thailand. Asian Anthropology, 14, 249-264. doi: 10.1080/1683478X. 2015.1117220

Norton, B. (2000). Identity and language learning: Gender, ethnicity and educational change. Harlow, England: Longman/Pearson Education.

Roulston, K. (2010). Reflective interviewing: A guide to theory and practice. London, UK: Sage.

Simon-Maeda, A. (2011). Being and becoming a speaker of Japanese: An autoenthnographic account. Bristol: Multilingual Matters.

Takahashi, K. (2013). Language learning, gender and desire: Japanese women on the move. Clevedon, UK: Multilingual Matters.

Takayama, K. (2000). Study abroad as contested space of global and local discourses: Japanese male students' study abroad experiences in Vancouver. The University of British Columbia, British Columbia. Retrieved from https://circle-ubc-ca.ezproxy.library.ubc.ca/bitstream/ handle/2429/10980/ubc_2000-0591.pdf?sequence=1

Taniguchi, S., \& McMahill, $\bar{C}$. (2015). Assimilation versus multiculturalism: Struggles over the meaning of 'tabunka kyōsei' in education for language 
minority children in Japan. In I. Nakane, E. Otsuji, \& W.S. Armour (Eds.), Language and identities in transitional Japan (167-188). New York: Routledge.

ELISABETH (LIBBY) MORINAGA-WILLIAMS, MA, is a PhD Candidate in Critical Studies in Transformative Education in Osaka University's Graduate School of Human Sciences. Her major research interests include critically exploring discourses of gender, race, language and identity among young people in Japan. Email: u819604i@ecs.osaka-u.ac.jp 